\title{
An Online Self Cold Startup Methodology for PEM Fuel Cells in Vehicular Applications
}

\author{
A. Amamou, Member, IEEE, M. Kandidayeni, Member, IEEE, S. Kelouwani, Senior Member, IEEE, \\ L. Boulon, Senior Member, IEEE
}

\begin{abstract}
This paper puts forward an adaptive cold start strategy for a proton exchange membrane fuel cell (PEMFC) based on maximum power mode. The proposed strategy consists of a water evacuation process after PEMFC shutdown and a selfheating process at PEMFC cold startup. To maximize the performance of the suggested strategy, an optimal operating condition for the cold start procedure is sought first. In this respect, an experimental parametric study is performed to explore the impact of fan velocity, micro-short circuit, anode pressure, and purge procedure on the PEMFC cold start performance. After laying down the proper conditions, the proposed cold start procedure is implemented on a test bench for experimental validations. The self-heating process is based on an online adaptive algorithm that maximizes the PEMFC's internal heat depending on its operating parameters' variation. In fact, this algorithm attempts to keep the current density at high levels, leading to PEMFC's performance improvement achieved by membrane hydration and temperature increase. The experimental results confirm the effectiveness of the proposed strategy, which presents a fast and cost-effective PEMFC's cold start.
\end{abstract}

Index Terms - Adaptive control, Cold start strategy, Kalman filter, Proton Exchange Membrane Fuel Cell, Vehicular applications

\section{INTRODUCTION}

$\mathrm{T}$ RANSPORTATION is a major pollution contributor, generating substantial quantities of nitrogen oxides, carbon monoxide, and other pollutants [1]. A wide range of technological solutions, such as hybrid electric vehicles (HEVs), battery vehicles, and fuel cell hybrid electric vehicles (FCHEVs) offer the potential to mitigate these impacts [2]. Among them, FCHEVs, which use a proton exchange membrane fuel cell (PEMFC) as the primary source and a battery pack as the secondary one, have gained great public and governmental recognition [3]. FCHEVs can be refueled in a few minutes, and used for a wide driving range $[4,5]$. In addition, they can reduce dependency on fossil fuels and offer potential reductions of greenhouse gases, especially when fueled with hydrogen from electrolysis or biomass [6]. Although FCHEVs are becoming increasingly important in the automotive sector, their market penetration and economic viability depend on the technological progress in the area of fuel cell lifetime, cost decline, and resolving the cold start issue in countries with cold weather conditions $[7,8]$.
PEMFC is an electro-chemical device that generates electricity by discharging heat and water. At cold temperature, the produced water freezes on the cathode and anode catalyst layer, which can block the passage of oxygen and hydrogen [9]. Furthermore, the water absorbed by the membrane can freeze, which slows down the electro-chemical reactions [9]. These phenomena cause a voltage and power drop, leading to the failure of the cold start and acceleration of the PEMFC degradation $[10,11]$.

In vehicular applications, a number of countries and institutions have imposed specific requirements for the PEMFC's cold startup. For instance, the US department of energy (DOE) has targeted a swift startup from $-20{ }^{\circ} \mathrm{C}$ in less than $30 \mathrm{~s}$ while consuming a low of $5 \mathrm{MJ}$ of energy in 2020 [12]. Moreover, they have aimed at a successful startup at -20 ${ }^{\circ} \mathrm{C}$ without utilizing an external heating source [12]. The European Union attempts to reach an effective cold startup at $25^{\circ} \mathrm{C}$ while sustaining a satisfying proton conductivity (over 10 $\mathrm{mS} . \mathrm{cm}-1$ at $-20^{\circ} \mathrm{C}$ ) [13]. Several studies have also proposed different strategies to improve the cold start quality of the PEMFC. These strategies fall into two groups of "Keep warm" and "Thaw at start" [14]. The former employs a thermal energy source to keep the PEMFC temperature near to its desirable range during the FCHEV parking time [15-18]. This methodology enhances the cold startup ability by protecting the PEMFC stack from freezing phenomenon. It can be effective for applications where the parking period is short and known a priori. However, when the parking period is long and not known, this method might become expensive concerning the required energy for heating the stack. The methods based on "Thaw at start" do not consume any energy during the parking time. Nevertheless, they demand a specific heat flow during the cold startup to rise the stack temperature from subfreezing condition to its desired operation range [19-32].

The strategies based on "Thaw at start" principle can be grouped into two categories of "Assisted cold start strategy" and "self-cold start strategies" according to the heating source [33, 34]. The first one requires an external heating source, such as heating element, hot air fan, battery, and catalytic burner, to escalate the PEMFC stack temperature during the startup [1923]. This category of strategies improve the heating time at the cost of decreasing the energy efficiency and increasing the cost of the system [33]. Moreover, the DOE has demanded an effective approach without the use of an external heating source [35]. Therefore, several researchers have turned attention to the development of "self-cold start strategies". These strategies are based on two steps: 1) purging procedure during the shutdown

Copyright (c) 2015 IEEE. Personal use of this material is permitted. However, permission to use this material for any other purposes must be obtained from the IEEE by sending a request to pubs-permissions@ieee.org 
to reduce water accumulation and decrease ice formation in the cathode catalyst layer; 2) a heating process during the start-up based on a self-heating solution. The methods based on selfheating employ the heat produced by the exothermic reaction and are divided into three types: galvanostatic startup (fixing the PEMFC current to the best current regarding the production of the heat inside PEMFC), potentiostatic startup (setting the PEMFC voltage to the best voltage which maximizes the exothermic heat production), and the maximum power mode startup.

Hishinuma et al. [30] and Lin et al. [27] propose a self-cold start strategy, based on purge procedure at shutdown and galvanostatic mode at start-up. This strategy is effective for a cold start from $-5^{\circ} \mathrm{C}$ but ineffective for lower temperatures. In order to increase the heat flux supplied by the galvanostatic solution and to provide a self-cold start from $-20^{\circ} \mathrm{C}$, Guo et al. [26] introduce an $\mathrm{O}_{2} / \mathrm{H}_{2}$ mixture on the anode side during the cold start. The majority of studies regarding the self-cold start strategy propose purging the PEMFC after shutdown and considering the potentiostatic mode at startup [24, 25, 28, 36]. This strategy is shown to be effective at cold startup from $20^{\circ} \mathrm{C}$. Qing et al. [37] propose a self-cold start strategy based on the PEMFC maximum power mode, and compare it with both potentiostatic and galvanostatic modes for a cold start from $-20^{\circ} \mathrm{C}$. They demonstrate that the maximum power mode is capable of balancing the heat production and the ice formation, resulting in an enhanced cold start survivability compared to the galvanostatic and potentiostatic solutions [37]. The potentiostatic, galvanostatic, and maximum power modes are efficient in terms of energy consumption, but heating time remains long for automotive applications [33].

One common issue of the above-discussed methods is that they are based on a set of precomputed parameters which are prone to alteration as the PEMFC undergoes performance drifts owing to operating conditions variation (temperature, membrane hydration, etc) and stack degradation. The degradation of a PEMFC is typically defined by the loss of voltage, which directly affects the rated power, through time $[38,39]$. Moreover, the extreme ambient conditions, such as subzero temperature, influence the output power of the PEMFC which in turn negatively impact the performance of the mentioned internal heating methods. So far, no PEMFC model has been proved to be able to accurately consider the degradation and the effect of ambient as well as the operating conditions, and it is still a study limitation in the literature. Therefore, some researches have been conducted to track the performance drifts of a PEMFC system in real-time based on extremum seeking strategies. These strategies offer two solutions. The first one mainly depends on the use of hill climbing methods $[40,41]$. For instance, in [40], a fractionalorder strategy is proposed to find an extremum value of a static nonlinear curve using a gradient optimization process. This strategy applies a periodic perturbation signal to the system input and then revises it toward the targeted objective point. Such methods are interesting due to their straightforward implementation. However, the perturbation signal is not simple to select during the cold startup of the PEMFC as it can increase the heating time and decrease the overall performance. The second solution is based on the use of an online parameter estimator coupled with an optimization algorithm [42, 43]. In this respect, the estimator updates the parameters of the mode online and then the required characteristics, such as maximum power, is extracted from the updated model. In [44], an adaptive cold start strategy is proposed to cope with the PEMFC parameters variation and to improve the cold start performance. However, the utilized model in this study does not take into account the temperature which is an important factor in cold start procedure.

The main objective of this paper is to develop an adaptive self-cold start strategy based on the maximum power mode of the PEMFC. In this regard, firstly, a parametric study is conducted to investigate the influence of PEMFC main parameters (anode pressure, fan speed, purge and micro shortcircuit) over cold start performance. Afterwards, the adaptive cold start strategy is developed using a multi-input semiempirical model of the PEMFC and Kalman filter, and its performance is experimentally validated by using three PEMFCs with different levels of degradation. Compared to other similar works, the main contributions of this paper are as follows:

- Performing a detailed parametric study to find the best operating parameters (anode pressure, fan speed, purge and micro short-circuit) for doing the PEMFC cold startup process (compared to [37, 44]).

- Employing a multi-input semi-empirical PEMFC model along with Kalman filter for accurate online estimation of maximum power in subfreezing condition (compared to $[37,44,45]$ ).

- Validating the performance of the proposed adaptive cold startup strategy by using three 500-W PEMFCs with different levels of degradation (compared to $[37,44])$.

The rest of the paper is organized as follows. Section II details the parametric study. Section III explains the adaptive cold start strategy. Section IV discusses the experimental results, and finally, the conclusion is given in section $\mathrm{V}$.

\section{PARAMETRIC STUDY}

During a self-cold startup, it is necessary to select the operating parameters in a way to maximize the generation of the heat inside the stack, which has a direct effect on the heating time. This section deals with the analysis of four important system parameters, namely anode pressure, fan velocity, purge, and short-circuit during the cold startup process to clarify the impact of each factor on the heating time. In this respect, the developed experimental set-up for testing the effect of each system's parameter is explained first. Subsequently, the reason for selecting each parameter is discussed. Finally, the experimental protocol, and the results regarding the influence of parameters on the cold startup are presented.

\section{A. Test bench}

The utilized test bench for the purpose of this work is presented in Fig. 1. This test bench includes an H500 Horizon open cathode PEMFC. It is self-humidified with a nominal power of $500 \mathrm{~W}$ (rated performance: 22V@23.5A), and 36 cells. This PEMFC has a dead-ended anode (DEA) configuration, which is fed by dry hydrogen at a controlled inlet 
pressure. A DEA configuration benefits from lower cost, volume, and weight compared to a flow-through system since it does not need a hydrogen recirculation loop and its auxiliary modules, including a pump, humidifier, and water separator [46]. However, there are also some issues regarding the DEA operation. Water accumulates in the anode catalyst layer and gas diffusion layer. Moreover, nitrogen of the air in the cathode side is added to the hydrogen gas in the anode channels by passing through the membrane [47]. Consequently, the anode side needs to be purged recurrently in order to remove accumulated water and nitrogen. At subzero temperature, the accumulated water can also freeze and fail the cold startup. Therefore, purging the residual water after shutdown and during PEMFC operation is necessary. The utilized PEMFC in this study is equipped with a purge valve to evacuate the produced water from the anode side. The purge procedure is divided into two phases. The first phase is related to the activation of the purge valve for $10 \mathrm{~ms}$ every $10 \mathrm{~s}$ during the operation of the PEMFC. This phase is common for all PEMFCs as it allows the evacuation of water and impurities generated during the normal operation. The second phase is related to winter condition and consists in purging the PEMFC after shutdown for $90 \mathrm{~s}$. Due to the open-cathode nature of the system, the cathode is always exposed to relatively dry ambient air. This configuration requires a system design which can keep the water in the MEA to achieve fast humidification [46]. Therefore, the bipolar plate on the anode side does not feature flow channels but an interdigitated flow field, which is integrated directly into the GDL. Moreover, fans are operated at high speed for a few seconds before each PEMFC shutdown to flush residual water out of cathode. It is also worth noting that both anode and cathode provide micro-porous layers (MPL) between GDL and CL, which avoid flooding phenomena and provide more space for ice formation. The anode and cathode flow field geometry of the studied stack as well as the structure of the diffusion layers have been discussed in details by Strahl et al. [48].

The minimum operating temperature of this PEMFC is around $0^{\circ} \mathrm{C}$ according to the manufacturer. It is equipped with two cooling fans to control the PEMFC temperature and to supply oxygen to the cathode side. Five thermistors are installed on different sides of the stack to measure the PEMFC temperature. One sensor is located in the center, two sensors are at the top-left and top-right corners, and two sensors are at the bottom-left and bottom-right corners. The stack temperature is equal to the average of all measurements. On the cathode side, the pressure is equal to the atmospheric pressure ( 1 bar). The pressure difference between the anode and the cathode must not exceed 0.6 bar to avoid membrane damage. PEMFC can also be short-circuited during normal operation, which promotes water production and heat. The generated water and heat generally favor the humidification of the membrane and improve the performance of the PEMFC.

The control of PEMFC auxiliaries, such as purge valve, anode pressure, fan speed, hydrogen valve, and short circuit, is performed through an NI CompactRIO programmable controller 9022. A programmable load with a maximum power of $1200 \mathrm{~W}$ is connected to the PEMFC to emulate the behavior of an electric motor. The PEMFC is placed inside a climatic room to simulate winter conditions. The volume of the climatic room is $0.39 \mathrm{~m}^{3}(85 \mathrm{~cm} \times 55 \mathrm{~cm} \times 85 \mathrm{~cm})$, oxygen consumption rate is $3.5 \mathrm{~L} / \mathrm{min}$, and the amount of oxygen in the climatic room is $81.7 \mathrm{~L}$, which is sufficient for the conducted tests.

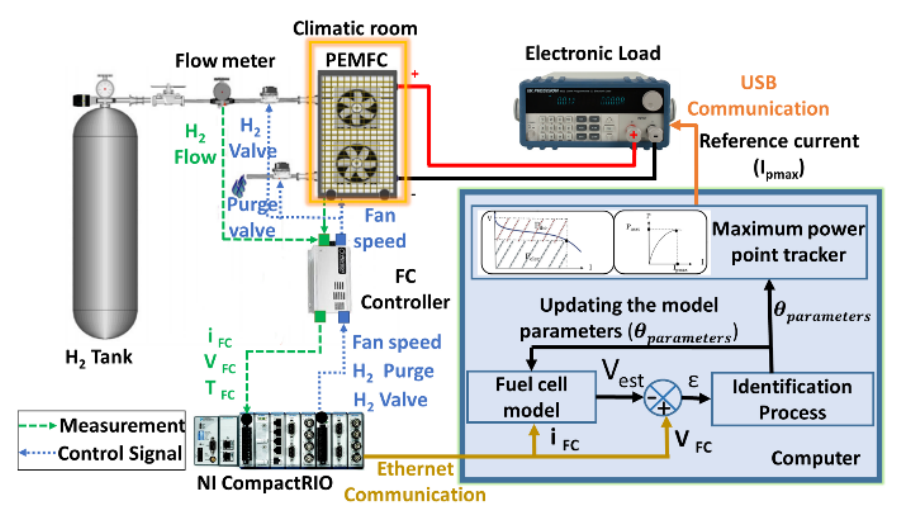

Fig. 1. The developed experimental setup for the cold startup test.

\section{B. Selected parameters}

The studied parameters are as follows:

- Fan speed: In the utilized open cathode PEMFC of this work, cooling fan has a dual role of controlling the amount of oxygen supplied to the stack and the regulation of temperature. Therefore, the speed of the fan is tuned depending on the requested power from the PEMFC and the stack temperature [49]. During the cold startup, it is desirable to increase the heat generation inside the stack for having a successful power rise. Therefore, it is important to determine the minimum fan speed which is sufficient for the reaction and cooling. A high fan speed is not recommended during the cold startup as it decreases the generation of the heat. To verify this choice, the cold start performance is studied by selecting two levels of $34 \%$ and $43 \%$ for the operation of the cooling fan duty cycle. $34 \%$ is the minimum required duty cycle preset in the controller of the PEMFC by the manufacturer, and $43 \%$ is just a higher duty cycle to show that increasing the fan speed is undesirable for the cold startup performance.

In an open cathode PEMFC, the airflow generated by the minimum duty cycle guarantees a high oxygen stoichiometry ratio at the rated power $[50,51]$. Concerning the employed PEMFC in this paper, the cathode stoichiometry is calculated by [50]:

$\left.S_{O_{2}}=\dot{n}_{\text {in }}^{O_{2}} /_{\dot{n}_{\text {cons }}^{O_{2}}}={ }^{0.21\left(\rho_{\text {air }} Q_{\text {air }} / M_{\text {air }}\right.}\right)\left.\right|_{N_{\text {cell }} \frac{I}{4 F}}$

where $S_{\mathrm{O}_{2}}$ is the oxygen stoichiometry, $\dot{n}_{i n}^{O_{2}}$ is the amount of oxygen supplied to the PEMFC, $\dot{n}_{\text {cons }}^{O_{2}}$ is the consumed oxygen in the electrochemical reaction, $\rho_{\text {air }}$ is the air density, $Q_{\text {air }}$ is the air flow, $M_{\text {air }}$ is the air molar mass, $N_{\text {cell }}$ is the number of cells, and $F$ is the Faraday constant. In (1), the only undefined parameter is the airflow $\left(Q_{\text {air }}\right)$, which is obtained using the presented experimental measurements in Fig. 2. 

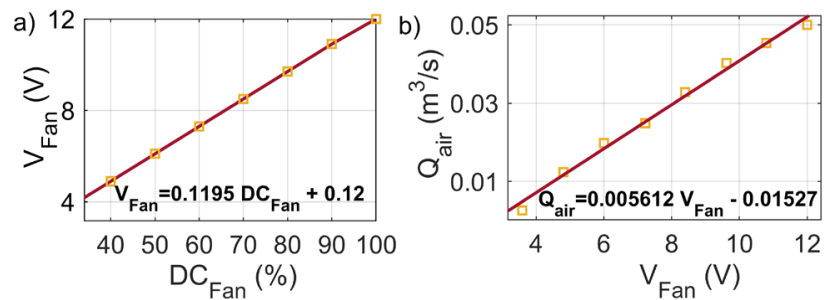

Fig. 2. Cooling fan characteristics, a) fan voltage with respect to duty cycle, and b) air flow with respect to fan voltage.

According to (1) and Fig. 2, even at the minimum duty cycle of the fan (34\%), a stoichiometry of around 33 is reached at the rated performance of the PEMFC (22V@23.5A).

- The micro-short circuit: The micro short-circuit provides a current peak for $10 \mathrm{~ms}$ every 10s in the utilized PEMFC stack. Activating the micro-short circuit leads to the increase of heat and water generation inside the PEMFC, which can improve the PEMFC cold startup. In normal operation, it is recommended to activate the micro-short circuit to enhance the performance of the stack in applications where the stack is not frequently used. However, the influence of this parameter on cold start performance has not been considered. Herein, the cold start performance is inspected with and without performing the micro short-circuit.

- Purging after shutdown: Literature study shows that purging the PEMFC after shut down reduces ice formation on the cathode which in turn improves the PEMFC cold start [52, 53]. In this regard, the influence of purging on the heating time is of interest in this study. To justify the effect of purging, the cold startup performance is investigated with and without purging the PEMFC after shutdown.

- Anode pressure: The performed analysis of the anode pressure effect on the cell potential in [54] shows that the increase of hydrogen partial pressure to a certain range leads to the reduction of concentration loss which increases the cell potential. In fact, rising the pressure level in the anode side leads to the increase of hydrogen permeation through the membrane which promotes the reaction at the cathode and resulting in the increase of voltage and temperature. However, further rise of the hydrogen partial pressure results in lower membrane hydration owing to the reduction of water vapor diffusivity. In this study, the cold startup is tested for two anode pressure levels of 0.45 bar and 0.6 bar. 0.45 bar corresponds to the minimum pressure recommended by the manufacturer, and 0.6 bar is the maximum authorized pressure.

With respect to the discussed matters, two levels are considered for each parameter in this work. Therefore, the number of possibilities comes to 16 for four parameters with two levels. More levels for each factor could be selected. However, the number of possibilities would become very high. Moreover, heuristically, the selection of more levels is not required considering the aforementioned explanation for each parameter. The $2^{\mathrm{k}}$ model ( $\mathrm{k}$ factors with 2 levels each) is the most widely used model as it allows several factors to be inspected at no extra cost [55]. Moreover, the experimental tests show that two levels are adequate for adjusting the parameters.

\section{Experimental protocol}

An experimental protocol has been developed to determine the parameters that minimize the heating time. In this work, heating time refers to the required time for the evolution of the PEMFC temperature from $-20{ }^{\circ} \mathrm{C}$ to the stack minimum operating temperature $\left(0{ }^{\circ} \mathrm{C}\right)$. The experimental plan is composed of 16 tests representing all possible combinations of the discussed parameters. Each test has three or four steps:

1. Normal operation of PEMFC at the current level of $10 \mathrm{~A}$ and an ambient temperature of $20^{\circ} \mathrm{C}$ for 15 minutes.

2. After 15 minutes of normal operation, the PEMFC is placed in the chamber of $-20^{\circ} \mathrm{C}$ for 8 hours. The 8 -hour conditioning time corresponds to the required time to stabilize the temperature of the PEMFC at $-20{ }^{\circ} \mathrm{C}$.

3. At the beginning of the conditioning phase, the PEMFC is still hot and most of the produced water is in a gaseous state. When the PEMFC cools down and most of the water turns to a liquid state (around $5^{\circ} \mathrm{C}$ ), the purge valve is activated for 90 seconds to evacuate the residual water. Purging temperature and duration are selected based on [33, 56-58]. This step presents "'Purging at shutdown', factor.

4. After 8 hours of conditioning at $-20{ }^{\circ} \mathrm{C}$, the PEMFC cold startup is performed by asking a constant voltage of $15 \mathrm{~V}$. The constant voltage mode is chosen to keep the same electrical parameters for all the tests. The constant voltage value $(15 \mathrm{~V})$ is in fact the rated voltage of the tested PEMFC at $-20^{\circ} \mathrm{C}$. The heating time is reported for each test. Each test has been repeated twice to ensure the accuracy of the results.

\section{Results analysis}

The factorial experiment is used to analyze the impact of the selected system parameters on the heating time. This experiment clarifies the effect of each parameter and the effect of interactions between parameters on the heating time. Minitab software is used for the design and analysis of the factorial experiment. The result of the factorial experiment is presented by a Pareto chart of effects in Fig. 3. The Pareto chart shows the absolute values of the normalized effects, ordered from the highest to the lowest. This diagram also includes a reference line which determines the statistically significant parameters. In Fig. 3, the bars that intersect the reference line are statistically important. That means the bars representing the "fan speed" (A) "purging at shutdown" (B), "micro short-circuit" (C) and "anode pressure" (D) intersect the reference line at 1.4 and have substantial impact on the heating time. Since the Pareto plot shows the absolute value of the effects, the level of parameters to increase or decrease the heating time cannot be determined. 


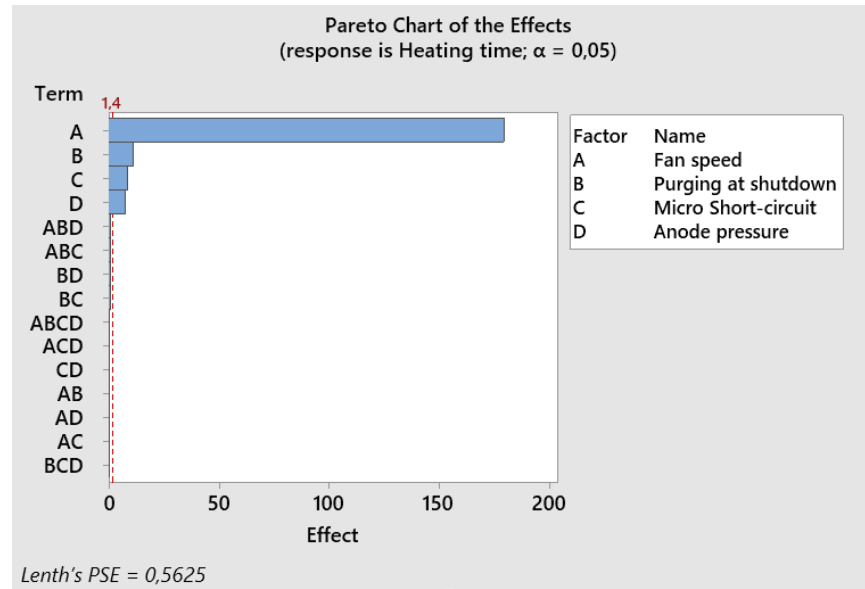

Fig. 3. Pareto chart of the parameters' effect on the heating time.

In this respect, the normal probability plot of the parameters' effect is presented in Fig. 4 to illustrate the importance and direction of effects. The normal probability plot indicates the position of the normalized effects with respect to the red line, which represents the case where all the effects would be 0 . The positive effects increase the response when the factor state changes from the low level to the high level. Negative effects decrease response when factor state changes from low level to the high level. Effects farthest from 0 are statistically more significant. Fig. 4 confirms that the effects of A, B, C and D are statistically substantial. Concerning the direction of the effects, the parameters $\mathrm{A}$ and $\mathrm{C}$ have a positive normalized effect. As these parameters go from the low level to the high level, the heating time increases. The parameters $\mathrm{B}$ and $\mathrm{D}$ have negative normalized effects. When these two factors go from the low level to the high level, the heating time decreases.

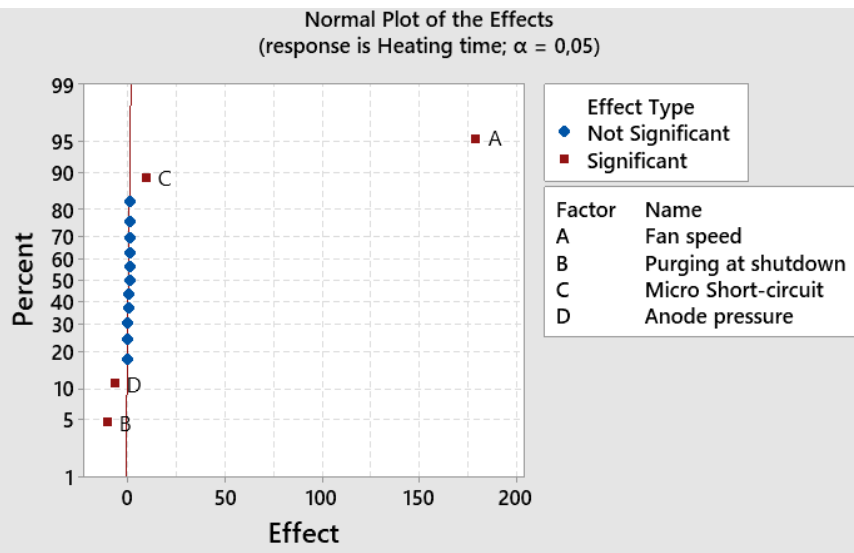

Lenth's PSE $=0,5625$

Fig. 4. Normal probability plot of the parameters' effects on the heating time.

To summarize, by decreasing the fan speed from high level to low level, the heating time considerably decreases (179 s). Therefore, during PEMFC cold start, the fan speed should be fixed at the minimum level which provides enough air to operate the PEMFC in the whole power range. Regarding the micro short-circuit, its activation increases the heating time $(8$ s). This increase is due to the fact that the water produced by micro short-circuit freezes at low temperature and affects the cold start performance. On the other hand, purging the PEMFC during shutdown reduces the heating time (11 s). Many studies have shown the effectiveness of the purge procedure in cold startup as it prevents the freezing of the residual water [59-62]. Concerning the anode pressure, the Pareto diagram shows that the pressure rise from 0.45 bar to 0.6 bar decreases the heating time $(7 \mathrm{~s})$. Therefore, the anode pressure should be set at its maximum authorized level. Table I shows the most suitable parameters for developing a cold startup strategy. These parameters are used in the adaptive cold startup strategy discussed in the next section.

TABLE I

THE TUNED OPERATING PARAMETERS OF THE PEMFC SYSTEM FOR COLD STARTUP PROCESS

\begin{tabular}{ll}
\hline \hline Parameters & Value or state \\
\hline Fan velocity & Minimum operational fan velocity \\
Micro short-circuit (C) & Disabled \\
Purge after Shutdown (P) & Enabled \\
Pressure (S) & The maximum authorized pressure \\
\hline \hline
\end{tabular}

\section{ADAPTIVE COLD START STRATEGY}

\section{A. Maximum power mode}

During the cold startup, it is important to maximize the generated exothermic heat inside the PEMFC to rapidly increase the stack temperature. Fig. 5 shows that as the drawn current from the PEMFC increases, more heat is generated by the exothermic reaction. However, reaching very high current level (low voltage level) can also result in the failure of the PEMFC cold start [24]. In fact, at high current levels, the concentration of oxygen and hydrogen decreases which leads to gases' partial pressure drop inside the PEMFC [63, 64]. This phenomenon causes a drop in cell voltage commonly known as concentration loss [9]. The PEMFC stack has a current threshold (corresponding to the maximum power) and exceeding this limit results in an increase in concentration loss and PEMFC degradation [33]. Therefore, it is suggested to operate the PEMFC at its maximum power $\left(\mathrm{P}_{\max }\right)$ during cold startup. This mode of operation does not require the external heating sources and maximizes the residual heat and electrical power while avoiding concentration loss and degradation of the stack. The maximum power mode is one of the most effective self-cold start strategies because it can better balance the heat generation and ice formation, leading to improved cold start survivability $[37,44]$. Nevertheless, it cannot be assumed that the PEMFC maximum power is constant during a cold startup since it is strongly influenced by degradation and the variation of operating conditions, such as pressure, temperature, and so forth [45, 65-67]. Moreover, some phenomena, including the increase of concentration loss due to the ice formation in the cathode catalyst and the reduction of ohmic and concentration loss due to the generated heat [33], affect the magnitude and location of the maximum power in a PEMFC. Therefore, it is important to identify the PEMFC maximum power online during the cold startup. 


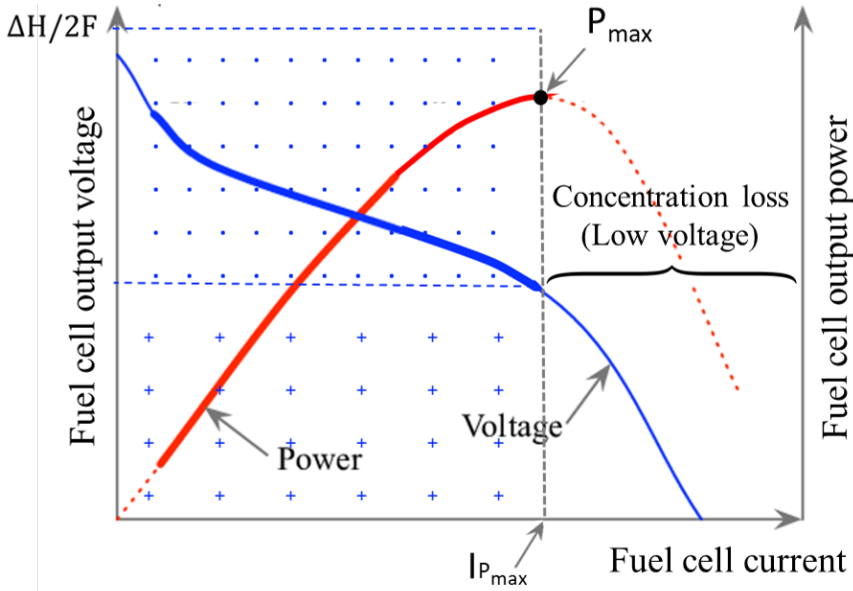

Power dissipated as heat

Power converted into electric power

$\left[\begin{array}{l}{ }_{++}^{++}+\cdots \\ +\end{array}\right.$

Fig. 5. Polarization and power curves of a 500-W PEMFC.

In this work, an adaptive process is developed to identify the PEMFC maximum power depending on PEMFC operating conditions and health state. This adaptive process is based on a recursive identification algorithm that updates the parameters of a PEMFC semi-empirical model in order to plot the PEMFC power curve in real time. The maximum power point is updated in real time using a maximum power point tracker algorithm, and the current corresponding to the maximum power is imposed to the PEMFC during the cold start. The flow chart of the global cold start strategy is shown in Fig. 6.

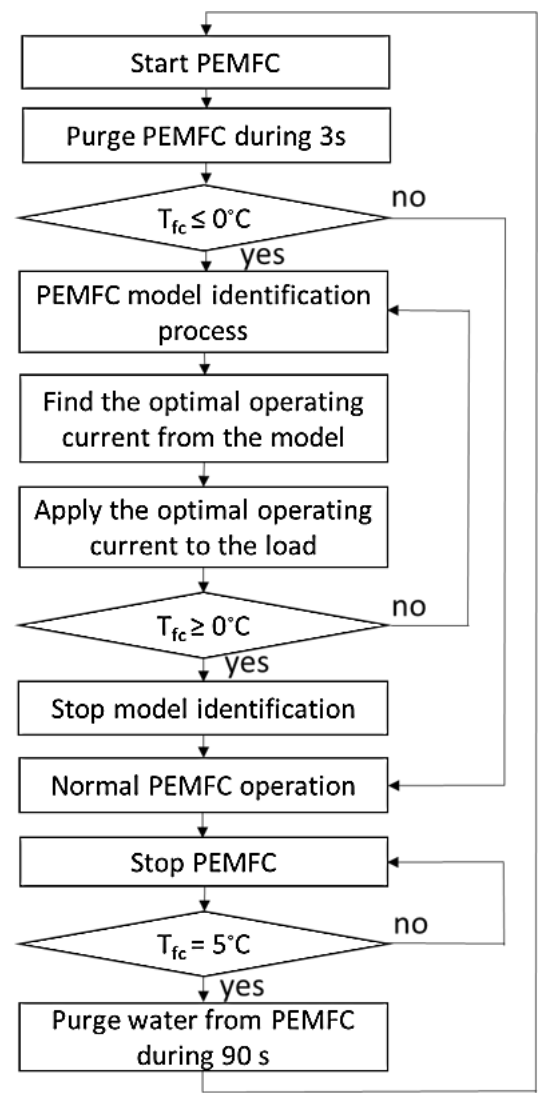

Fig. 6. Flow chart of the global cold start strategy.

\section{B. Purge procedure at shutdown}

In automotive applications, purge duration is very important because additional energy is consumed during the purge process and must be controlled to prevent the membrane dehydration [68]. Several studies have shown that a short purge time does not eliminate enough residual water which in turn increases the freezing potential inside the stack [69]. On the other hand, a long purge time increases the membrane resistance, which limits the PEMFC current and thus reduces the produced heat [70]. Based on literature, it is confirmed that the purge duration of 90-120 s is suitable for FCHEVs [71, 72]. In this respect, the duration of purge is set to $90 \mathrm{~s}$ in the adaptive cold start strategy of this paper.

The PEMFC temperature is also crucial for the effectiveness of purge procedure $[56,73]$. After shutdown, the PEMFC is still warm and the produced water inside the PEMFC is in gaseous state. Therefore, it is preferable to wait until the PEMFC temperature decreases and water state changes from the gaseous to liquid. Once the water is in a liquid state, it must be purged before the PEMFC temperature reaches the freezing temperature. Based on [56], the PEMFC purge temperature is set to $5^{\circ} \mathrm{C}$.

\section{Adaptive algorithm for maximum power identification}

The heating procedure is based on an adaptive PEMFC current control to maximize the produced exothermic heat during cold start. This process is performed in 3 steps, shown in Fig. 7, as follows:

1. Updating the parameters of a PEMFC model using an online identification algorithm to plot the present state PEMFC power curve.

2. Finding the operating current level corresponding to the PEMFC's maximum power. This operating current is updated every $100 \mathrm{~ms}$.

3. Applying the identified current level to the PEMFC stack.

It should be noted that as soon as the PEMFC temperature reaches $0^{\circ} \mathrm{C}$, the control process will be stopped.

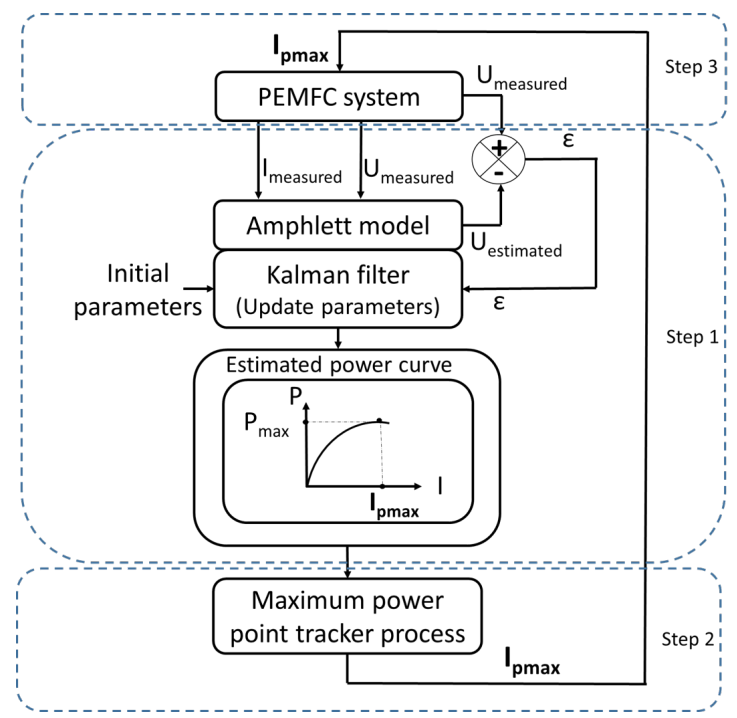

Fig. 7. The adaptive control process. 


\section{Fuel cell semi-empirical model}

The choice of the semi-empirical model is crucial for the identification process because the model structure greatly influences the accuracy of the estimation. In [45], a comparative study of different semi-empirical models is performed and concluded that the model proposed by Amphlett et.al [74] is adequately precise for reproducing the PEMFC electrochemical behavior. Amphlett model estimates the PEMFC output voltage by taking several inputs (current, pressure, and temperature) into account. This model can be presented by the following equations.

$$
\begin{aligned}
& V_{f c}=N V_{c e l l} \\
& V_{\text {cell }}=E_{\text {Nernst }}+\eta_{\text {act }}+\eta_{\text {ohmic }}+\eta_{\text {con }} \\
& E_{\text {Nernst }}=1.229-0.85 \times 10^{-3}\left(T_{f c}-298.15\right) \\
& +4.3085 \times 10^{-5} T_{f c}\left[\ln \left(P_{H 2}\right)\right. \\
& \left.+0.5 \ln \left(P_{O 2}\right)\right] \\
& \left\{\begin{array}{l}
\eta_{a c t}=\xi_{1}+\xi_{2} T_{f c}+\xi_{3} T_{f c} \log \left(\mathrm{CO}_{2}\right)+\xi_{4} T_{f c} \log \left(i_{f c}\right) \\
\mathrm{CO}_{2}=\frac{P_{O 2}}{5.08 \times 10^{6} \exp \left(-498 / T_{f c}\right)}
\end{array}\right. \\
& \eta_{\text {ohmic }}=-i_{f c} R_{\text {internal }}=-i_{f c}\left(\mu_{1}+\mu_{2} T_{f c}+\mu_{3} i_{f c}\right) \\
& \eta_{\text {con }}=B \log \left(1-\frac{J_{f c}}{J_{\max }}\right)
\end{aligned}
$$

Where, $V_{f c}$ is the PEMFC output voltage (V), $V_{\text {cell }}$ is the cell output voltage $(\mathrm{V}), N$ is the number of cells, $E_{\text {Nernst }}$ is the reversible cell potential $(\mathrm{V})$ [75], $V_{\text {act }}$ is the activation loss $(\mathrm{V})$, $V_{\text {onmic }}$ is the ohmic loss $(\mathrm{V}), V_{\text {con }}$ is the concentration loss $(\mathrm{V}), T$ is the stack temperature $(\mathrm{K}), P_{O 2}$ is the cathode oxygen partial pressure $\left(\mathrm{N} \mathrm{m}^{-2}\right), P_{H^{2}}$ is the anode hydrogen partial pressure (N $\left.\mathrm{m}^{-2}\right), \varepsilon_{n}(\mathrm{n}=1 . .4)$ are the semi-empirical coefficients based on electrochemistry, fluid mechanics and thermodynamics [76], $\mathrm{CO}_{2}$ is the oxygen concentration ( $\left.\mathrm{mol} \mathrm{cm}{ }^{-3}\right), i_{f c}$ is the PEMFC operating current (A), $R_{\text {internal }}$ is the internal resistor $(\Omega), \mu_{n}$ $(\mathrm{n}=1 \ldots 3)$ are the parametric coefficients, $B$ is a parametric coefficient $(\mathrm{V}), J$ is the actual current density $\left(\mathrm{A} \mathrm{cm}^{-2}\right)$, and $J_{\max }$ is the maximum current density $\left(\mathrm{A} \mathrm{cm}^{-2}\right)$.

As explained in [77, 78], assuming that the PEMFC is a perfect isolated system, the entropy change becomes zero and the Gibbs free energy will be equal to the variations of enthalpy $\left(\Delta H_{f}\right)$. In this case, the maximum voltage $\left(V_{\max }\right)$ given by the overall conversion of enthalpy into electrical energy is obtained by:

$$
V_{\text {max }}=-\frac{\Delta H_{f}}{n_{e} F}
$$

where $F$ is the Faraday constant $\left(96485 \mathrm{C} \mathrm{mol}^{-1}\right), n_{e}$ is the number of electrons which is two in case of hydrogen in the overall PEMFC reaction $\left(\mathrm{H}_{2}+\frac{1}{2} \mathrm{O}_{2} \rightarrow \mathrm{H}_{2} \mathrm{O}\right), \Delta H_{f}=-285.84$ $\mathrm{kj} \mathrm{mol}^{-1}$ if the water product is in liquid form, and $\Delta H_{f}=$ $-241.83 \mathrm{kj} \mathrm{mol}^{-1}$ if the water product is in vapor form. The higher value for $\Delta H_{f}$ has been utilized in this study. It is called the higher heating value (HHV).

Under the condition $i_{F C}(t)>0$, the delivered voltage by the cell $\left(V_{\text {cell }}\right)$ is lower than the standard potential. Considering the fact that it is impossible to reach $V_{\max }$ in a PEMFC as there is always heat loss in form of entropy in the system which is calculated as follows.

$P_{\text {loss }}=i_{F C}\left(V_{\text {max }}-V_{\text {cell }}\right) N$

\section{$\underline{\text { Recursive identification algorithm }}$}

As previously described, the parameters of the PEMFC model are time-varying since its performance is influenced by degradation phenomenon and variation of operating conditions. In this respect, Kalman filter is utilized in this study to estimate the 8 parameters of the Amphlett model $\left(\xi_{1}, \xi_{2}, \xi_{3}, \xi_{4}, \mu_{1}, \mu_{2}, \mu_{3}, B\right)$ online. The choice of the recursive identification algorithm mainly depends on the structure of the estimated parameters (linear or nonlinear). Amphlett model emulate the non-linear behavior of a PEMFC stack, but the targeted parameters for estimation present a linear structure. In [45], a comparative study of different recursive identification algorithms showed the effectiveness of Kalman filter to estimate the linear parameters of Amphlett model with the lowest estimation error. In this regard, Kalman filter is employed to update in real-time the unknown parameters of the PEMFC model. The updated model is then used to plot the realtime power curve to find the PEMFC maximum power point during the cold startup. The details about the structure and initialization of Kalman filter for online estimation of the PEMFC model are comprehensively discussed in our previous work [45].

\section{EXPERIMENTAL VALIDATION OF THE GLOBAL ADAPTIVE STRATEGY}

\section{A. Experimental procedure}

In order to investigate the performance of the proposed adaptive cold startup strategy, three H500 Horizon PEMFCs with different degradation levels are utilized in this paper. These PEMFCs have already been utilized in different projects and conditions. Therefore, some of them have been under operation more than the others. Since the exact age of each fuel cell in terms of hour is not available, their present-day polarization and power curves in normal ambient temperature are presented in Fig. 8 to classify them in terms of degradation. The original polarization curve (i.e. initial polarization curve of a brand-new Horizon $500 \mathrm{~W}$ PEMFC) is also shown as the reference. It is well-known that as the PEMFC gets aged, its rated power decreases. Therefore, the relative aging level of each utilized PEMFC is assumed based on the experimentally obtained power curves. 

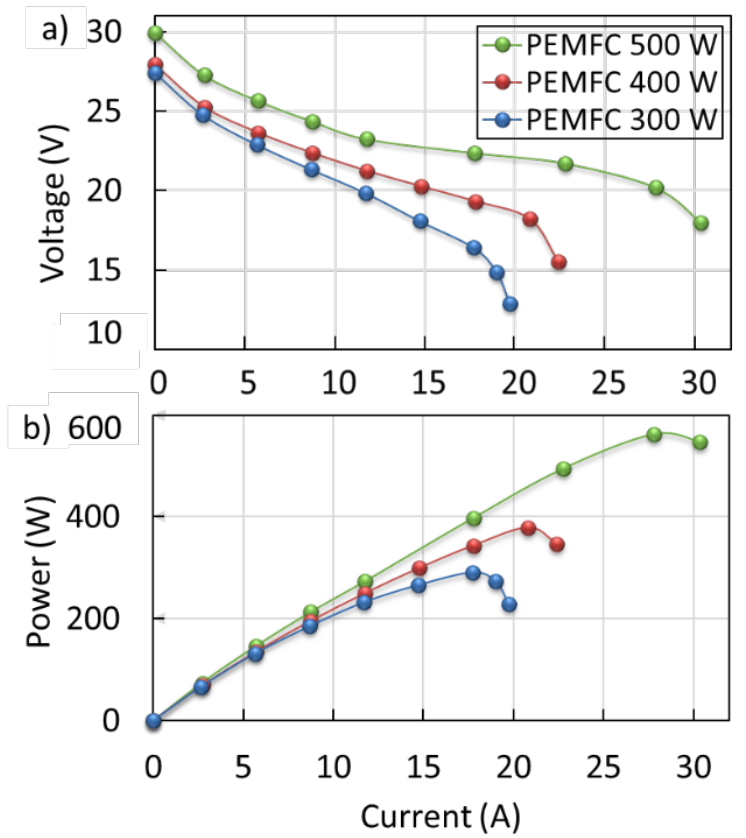

Fig. 8. Polarization and power curves of the three PEMFCs at $25^{\circ} \mathrm{C}$

Hereinafter in this manuscript, these PEMFCs are referenced by their rated powers at ambient temperature: $300 \mathrm{~W}, 400 \mathrm{~W}$ and $500 \mathrm{~W}$. The $500-\mathrm{W}$ PEMFC is a brand-new one. However, the other two PEMFCs have been degraded through time.

The three PEMFCs are purged according to the previouslyexplained procedure. After conditioning at $-20{ }^{\circ} \mathrm{C}$ for $8 \mathrm{~h}$, the adaptive algorithm is lunched to start the PEMFCs from $-20^{\circ} \mathrm{C}$. In the first step, Kalman filter receives the measured current, voltage, and temperature data from the PEMFC via Ethernet communication every $100 \mathrm{~ms}$. In the second step, it estimates the parameters of the Amphlett model. Afterwards, the updated model is used to plot the power curve. Finally, the operating current corresponding to the maximum power is identified and sent to the programmable load via USB communication. The process is done in real-time until PEMFC temperature reach $0^{\circ} \mathrm{C}$.

\section{B. Experimental results}

In this section, the performance of the suggested adaptive cold start strategy is scrutinized from different perspectives. Initially, the evolution of the main operating parameters (current, voltage, and temperature) as well as the generated electrical and thermal power are discussed for each PEMFC during a cold startup test from $-20{ }^{\circ} \mathrm{C}$. Subsequently, the reached heating time and consumed energy of each case study are compared. Moreover, to illuminate the impact of initial temperature on the consumed energy and heating time during cold startup, four cold startup tests with different initial temperatures are conducted over the 400-W PEMFC. This section comes to an end by verifying the performance of the online identification method which has a significant role in the performance of the proposed cold startup method.

Fig. 9 demonstrates the evolution of the current, voltage, and temperature during the performed cold startup test for the three PEMFCs. Fig. 9a shows that in all the PEMFCs, the current increases during the first seconds, followed by a rapid drop.
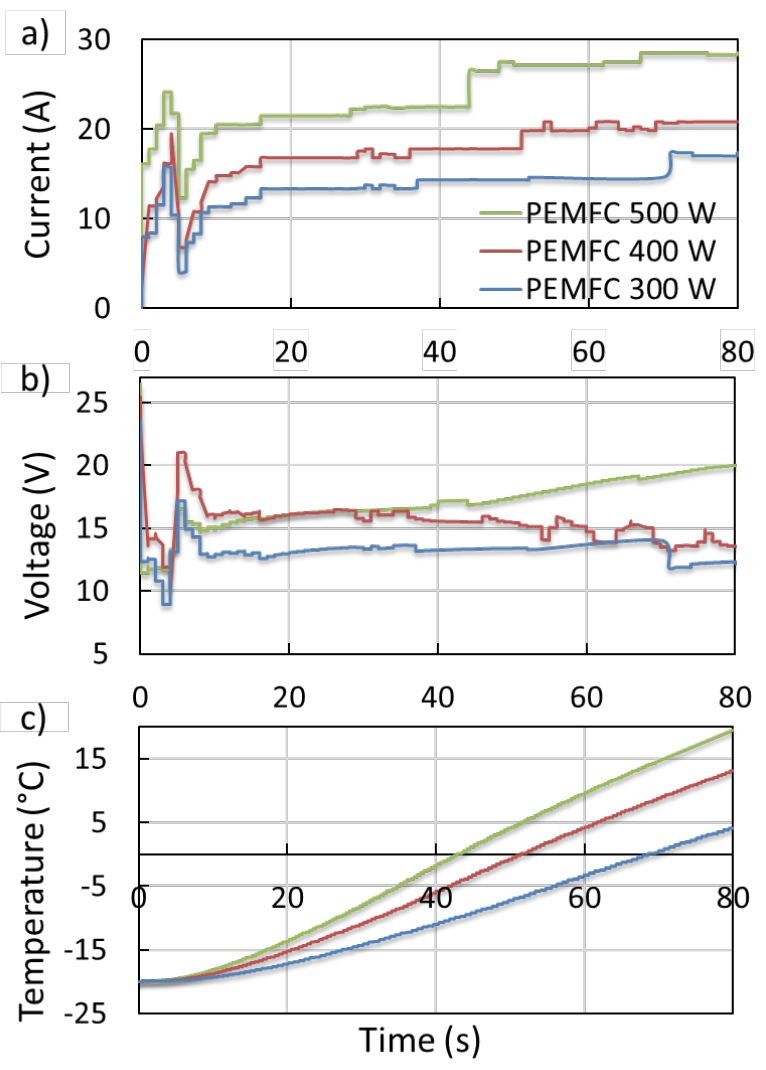

Fig. 9. Evolution of current (a), voltage (b) and temperature (c) of the three PEMFCs during an adaptive cold start from $-20^{\circ} \mathrm{C}$

After that it increases smoothly until becoming almost stable. In fact, the algorithm increases the current during the first few seconds due to the membrane hydration, which lowers the ohmic resistance and enhances the reaction kinetics, and the following decrease is mainly caused by the ice formation [37]. Owing to the sharp voltage drop, the algorithm decreases the PEMFC current to adapt to the state of the frozen PEMFC and avoid the cold start failure. As the current has a rising tendency, the stack temperature is almost on the rise during the whole test (Fig. 9c).

Fig. 10 shows the electrical and thermal power trends. The thermal power has been calculated based on (9) and (10). According to Fig. 10a, from 0 to almost $6 \mathrm{~s}$, the electrical power has a sharp rise followed by a drop. It then gradually increases through time for each PEMFC. The intensity of this increase is different in each PEMFC as they have different degradation levels. Fig. 10b illustrates that the thermal power has also experienced a similar trend to the electrical power as they both depend on the drawn current from the stack. In fact, the produced heat, during the first seconds, raises the PEMFC temperature which improves the PEMFC performance and therefore allows the algorithm to gradually increases the PEMFC current. 
a)
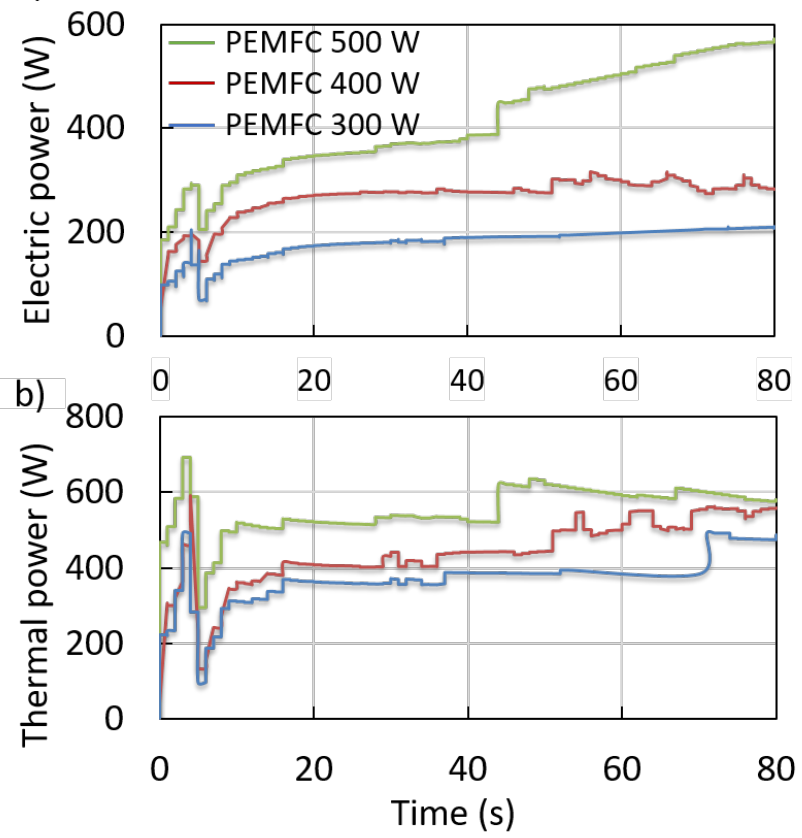

Fig. 10. Evolution of electrical power (a) and thermal power (b) of the three PEMFCs during an adaptive cold start from $-20^{\circ} \mathrm{C}$

Table II presents the required current to reach the maximum power and the corresponding thermal power of each utilized PEMFC stack at two different temperatures. An important point that needs to be underlined here is the influence of temperature variation and PEMFC degradation on the maximum power point values. According to this table, the 500-W PEMFC reaches higher current levels than the other ones during cold startup. The PEMFC current level, which significantly changes during the cold start process, directly reflects the rate of water and heat production inside the stack. Table II also indicates that the 500-W PEMFC produces more heat compared to other two PEMFCs during the cold start which makes this PEMFC faster in terms of reaching the temperature level of $0{ }^{\circ} \mathrm{C}$. Therefore, this analysis justifies the rapid temperature rise of the $500-\mathrm{W}$ PEMFC from $-20^{\circ} \mathrm{C}$ to $0^{\circ} \mathrm{C}$ in $43 \mathrm{~s}$, compared to $51 \mathrm{~s}$ for the $400-\mathrm{W}$ PEMFC and $68 \mathrm{~s}$ for the $300-\mathrm{W}$ PEMFC as shown in Fig. 11. From Fig. 11, the effect of degradation on the performance of the proposed strategy can be realized. The degradation of the PEMFC causes a rise on heating time because the maximum power as well as the produced thermal power decrease when the PEMFC is degraded. The heating time and the PEMFC power are different for the three PEMFCs during cold start, which affects the energy consumption. It is important to note that the consumed energy for the purge procedure is included in the presented energy consumption of the adaptive cold start strategy in Fig. 11. The experimental validation of the proposed strategy was repeated 20 times for each PEMFC with a standard deviation of $5 \mathrm{~s}$ regarding the heating time and $54 \mathrm{~J} \mathrm{~cm}^{-2}$ concerning the energy consumption.
TABLE II

CURRENT CORRESPONDING TO MAXIMUM POWER ( I $_{\text {PMAX }}$ ), MAXIMUM POWER ( $\mathrm{P}_{\text {MAX }}$ ) AND THERMAL POWER DURING THE

\begin{tabular}{|c|c|c|c|c|}
\hline 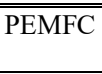 & "Temperature & 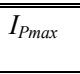 & $\overline{P P_{\max }}$ & $\begin{array}{l}\text { Thermal } \\
\text { power }\end{array}$ \\
\hline \multirow[t]{2}{*}{$300 \mathrm{~W}$} & $-15^{\circ} \mathrm{C}$ & $\begin{array}{l}13.5 \\
\text { A }\end{array}$ & $\begin{array}{l}180 \\
W\end{array}$ & $358 \mathrm{~W}$ \\
\hline & $3^{\circ} \mathrm{C}$ & $\begin{array}{l}14.31 \\
\mathrm{~A}\end{array}$ & $\begin{array}{l}196 \\
\text { W }\end{array}$ & $387 \mathrm{~W}$ \\
\hline \multirow[t]{2}{*}{$400 \mathrm{~W}$} & $-15^{\circ} \mathrm{C}$ & $17 \mathrm{~A}$ & $\begin{array}{l}275 \\
W\end{array}$ & $400 \mathrm{~W}$ \\
\hline & $3^{\circ} \mathrm{C}$ & $20 \mathrm{~A}$ & $\begin{array}{l}305 \\
\text { W }\end{array}$ & $493 \mathrm{~W}$ \\
\hline \multirow[t]{2}{*}{$500 \mathrm{~W}$} & $-15^{\circ} \mathrm{C}$ & $21 \mathrm{~A}$ & $\begin{array}{l}340 \\
W\end{array}$ & $533 \mathrm{~W}$ \\
\hline & $3^{\circ} \mathrm{C}$ & $\begin{array}{l}28.3 \\
\text { A }\end{array}$ & $\begin{array}{l}561 \\
\text { W }\end{array}$ & $579 \mathrm{~W}$ \\
\hline
\end{tabular}

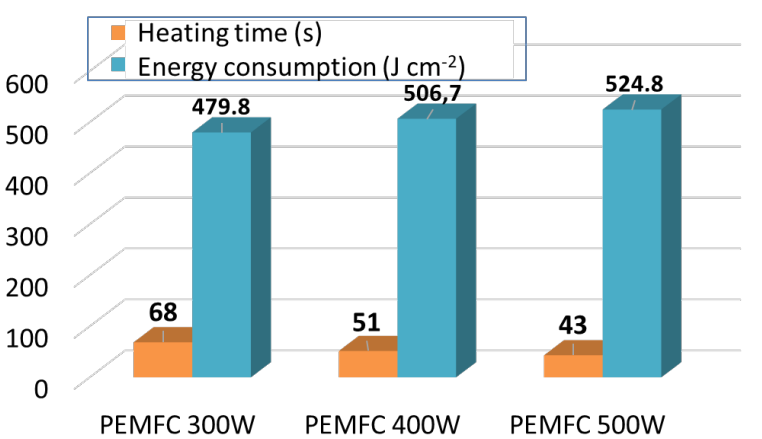

Fig. 11. Heating time and energy consumption of the three PEMFCs during the adaptive cold startup from $-20^{\circ} \mathrm{C}$

Fig. 12 compares the performance of the adaptive strategy in different initial temperatures. According to this figure, the duration to achieve the melting point as well as the consumed energy changes almost linearly with the start-up temperature.

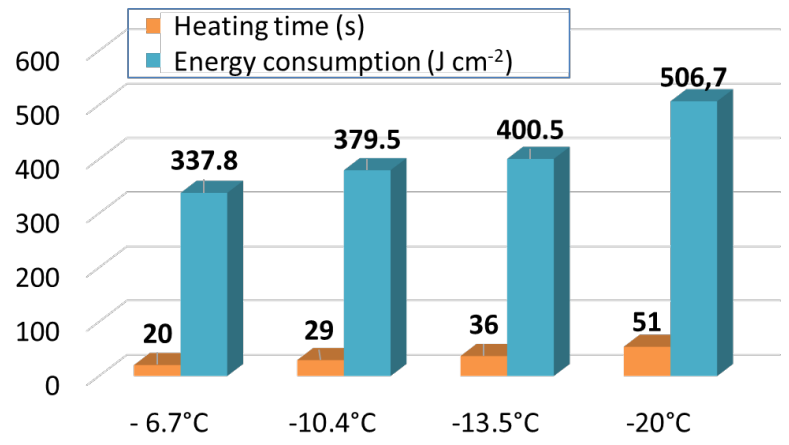

Fig. 12. Cold startup performance of the 400-W PEMFC for different initial temperatures

To confirm the accuracy of the online parameter identification process, the physical relevance of the estimated PEMFC resistance is studied for the 400-W PEMFC. Table III compares the estimated and the calculated membrane resistance at two different temperatures. The estimated membrane resistance $\left(R_{\text {internal }}\right)$ by the Amphlett model depends on the current, temperature, and the three empirical parameters $\left(R_{\text {internal }}=\mu_{1}+\mu_{2} T_{f c}+\mu_{3} i_{f c}\right)$. The calculated membrane resistance is deducted from the slope of the linear region of the measured polarization curve at the given temperature. This 
slope is approximately equal to the PEMFC internal resistance. From Table III, the calculated values of $R_{\text {internal }}$ are in agreement with the estimated values. Fig. 13 also shows the evolution of the estimated resistance by the online PEMFC model for the 400-W PEMFC. As is seen in this figure, $R_{\text {internal }}$ gradually decreases during the cold startup process. This is due to the fact that $R_{\text {internal }}$ is dependent on the stack temperature, and therefore, the rise of temperature results in the hydration of the membrane.

TABLE III

THE ESTIMATED AND CALCULATED VALUE OF THE MEMBRANE RESISTANCE (R INTERNAL)

\begin{tabular}{lll}
\hline \hline Temperature & $-15^{\circ} \mathrm{C}$ & $1^{\circ} \mathrm{C}$ \\
Estimated resistance & $0.315 \Omega$ & $0.265 \Omega$ \\
Calculated resistance & $0.357 \Omega$ & $0.273 \Omega$ \\
\hline \hline
\end{tabular}

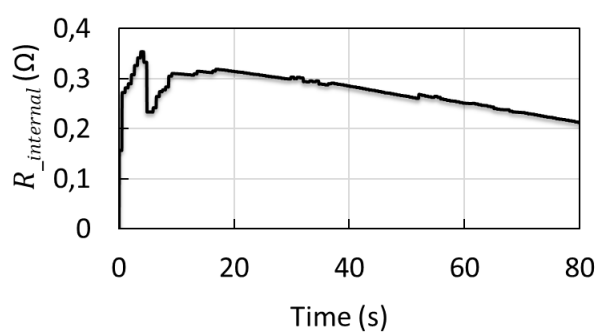

Fig. 13. Evolution of the estimated resistance of the Amphlett model during an adaptive cold startup test with the 400 -W PEMFC from $-20^{\circ} \mathrm{C}$

\section{CONCLUSION}

This paper presents an adaptive cold startup strategy for a PEMFC based on the prediction of the PEMFC maximum power point during the cold startup. The core of this strategy is a purge procedure before shutdown and a PEMFC maximum power point tracking algorithm. The maximum power point is identified using an online PEMFC model composed of a multiinput semi-empirical model and a Kalman filter. From the predicted power curve, the current corresponding to the maximum power is extracted and imposed to the PEMFC during the cold start. The proposed strategy is experimentally validated by using three 500-W PEMFCs with different degradation levels. In order to improve the performance of the cold startup strategy, a parametric study is also performed to tune the operating parameters of the PEMFC (fan speed, anode pressure, purge and micro short-circuit) for the cold startup test. The conducted parametric study reveals that the fan speed must be set to the minimum level to keep the produced heat inside the stack. Moreover, it shows that higher anode pressure is favorable as it decreases the heating time. Regarding the purge procedure after shutdown, it is confirmed that it is effective in improving cold start performance. However, the PEMFC short circuit during cold start shows a negative impact on the cold start performance and should be deactivated.

The experimental results show that the proposed adaptive strategy is perfectly functional for a cold startup from $-20^{\circ} \mathrm{C}$. It is capable of coping with the PEMFC parameters variation during cold startup and keeps the current density at high levels, resulting in the PEMFC performance improvement caused by membrane hydration and temperature increase. The adaptive strategy is economical in terms of energy consumption because it avoids external heating by maximizing the PEMFC internal heat and avoiding operating the PEMFC at low voltage levels.

The outcomes of this paper put forward the following directions for future studies:

- The proposed adaptive strategy has been experimentally validated for three 500-W PEMFCs. The latest DOE target for the cold startup of the FCHEV is an 80-kW PEMFC at -20 in less than 30s and less than $5 \mathrm{MJ}$ of energy. Therefore, the adaptive strategy of this work should be scaled up in future.

- The impact of the suggested adaptive strategy on the PEMFC lifetime should be studied.

- The operating temperature of the proposed strategy is limited to $-20^{\circ} \mathrm{C}$. For lower operating temperatures, more focus should be given to the development of an online ice estimation algorithm combined with a hybrid cold start solution. This algorithm should be based on an adaptive maximum cold start mode, as the main cold start solution, and an external heating method used when cathode catalyst layer is blocked by ice.

- In this article, an open-cathode PEMFC is used because it benefits from a simpler and faster experimental implementation. Unlike the typical liquid-cooled automotive PEM fuel cells, an opencathode PEMFC system requires no compressor, humidifier, hydrogen recirculation pump or water coolant loop, which dramatically simplifies system design. Therefore, more concrete studies are required in future to focus on experimental performance evaluation of the proposed strategy in sub-freezing conditions with a water-cooled PEMFC.

\section{ACKNOWLEDGEMENTS}

This work was supported in part by the Bureau de l'éfficacité et de l'innovation énergétique, Ministère des Ressources Naturelles et de la Faune du Québec, the Natural Sciences and Engineering Research Council of Canada (NSERC), the Fonds de recherche du Québec-Nature et technologies (FRQNT), and Canada Research Chairs program.

\section{REFERENCES}

C. Dépature, W. Lhomme, P. Sicard, A. Bouscayrol, and L. Boulon, "Real-Time Backstepping Control for Fuel Cell Vehicle Using Supercapacitors," IEEE Transactions on Vehicular Technology, vol. 67, no. 1, pp. 306-314, 2018, doi: 10.1109/TVT.2017.2728823.

C. C. Chan, A. Bouscayrol, and K. Chen, "Electric, Hybrid, and Fuel-Cell Vehicles: Architectures and Modeling," IEEE Transactions on Vehicular Technology, vol. 59, no. 2, pp. 589-598, 2010, doi: 10.1109/TVT.2009.2033605.

3] A. M. Ali, A. Ghanbar, and D. Söffker, "Optimal Control of MultiSource Electric Vehicles in Real Time Using Advisory Dynamic Programming," IEEE Transactions on Vehicular Technology, vol. 68, no. 11, pp. 10394-10405, 2019, doi: 10.1109/TVT.2019.2941523.

X. Lü, Y. Qu, Y. Wang, C. Qin, and G. Liu, "A comprehensive review on hybrid power system for PEMFC-HEV: Issues and strategies," Energy Conversion and Management, vol. 171, pp. 1273-1291, 2018/09/01/ 2018, doi: https://doi.org/10.1016/j.enconman.2018.06.065. 
[5] B. Geng, J. K. Mills, and D. Sun, "Two-Stage Energy Management Control of Fuel Cell Plug-In Hybrid Electric Vehicles Considering Fuel Cell Longevity," IEEE Transactions on Vehicular Technology, vol. 61, no. 2, pp. 498-508, 2012, doi: 10.1109/TVT.2011.2177483

[6] S. Ziaeinejad, Y. Sangsefidi, and A. Mehrizi-Sani, "Fuel Cell-Based Auxiliary Power Unit: EMS, Sizing, and Current Estimator-Based Controller," IEEE Transactions on Vehicular Technology, vol. 65, no. 6, pp. 4826-4835, 2016, doi: 10.1109/TVT.2016.2552722.

[7] W. Schmittinger and A. Vahidi, "A review of the main parameters influencing long-term performance and durability of PEM fuel cells," Journal of Power Sources, vol. 180, no. 1, pp. 1-14, 5/15/ 2008, doi: http://dx.doi.org/10.1016/j.jpowsour.2008.01.070.

[8] C. Depature, A. Bouscayrol, and L. Boulon, "Range-Extender Electric Vehicle Using a Fuel Cell," in 2013 IEEE Vehicle Power and Propulsion Conference (VPPC), 15-18 Oct. 2013 2013, pp. 16, doi: 10.1109/VPPC.2013.6671702.

[9] Y. Luo and K. Jiao, "Cold start of proton exchange membrane fuel cell," Progress in Energy and Combustion Science, vol. 64, pp. 2961, 2018, doi: 10.1016/j.pecs.2017.10.003.

[10] Z. Wan, H. Chang, S. Shu, Y. Wang, and H. Tang, "A review on cold start of proton exchange membrane fuel cells," Energies, vol. 7, no. 5, pp. 3179-3203, 2014, doi: 10.3390/en7053179.

[11] H. Meng and B. Ruan, "Numerical studies of cold-start phenomena in PEM fuel cells: A review," International Journal of Energy Research, vol. 35, no. 1, pp. 2-14, 2011.

[12] (2016). Multi-Year Research, Development, and Demonstration Plan. [Online] Available: https://energy.gov/eere/fuelcells/downloads/fuel-cell-technologiesoffice-multi-year-research-development-and-22

[13] Y. Luo, Q. Guo, Q. Du, Y. Yin, and K. Jiao, "Analysis of cold start processes in proton exchange membrane fuel cell stacks," Journal of Power Sources, vol. 224, pp. 99-114, 2013, doi: 10.1016/j.jpowsour.2012.09.089.

[14] A. Amamou, L. Boulon, S. Kelouwani, K. Agbossou, and P. Sicard, "Thermal Management Strategies for Cold Start of Automotive PEMFC," presented at the Vehicle Power and Propulsion Conference (VPPC), 2015 IEEE, Montreal, 2015.

[15] W. S. Wheat, M. A. Meltser, and D. A. Masten, "Fuel cell energy management system for cold environments System for cold environment," US Patent 6,727,013 B2, 2004. [Online]. Available: https://www.google.ca/patents/US6727013

[16] B. J. Clingerman et al., "Fuel cell system water management strategy for freeze capability," US Patent 2007/0298289 A1, 2007. [Online].

Available: https://www.google.ca/patents/US20070298289

[17] A. A. Pesaran et al., PEM fuel cell freeze and rapid startup investigation. Golden, Colo.: National Renewable Energy Laboratory (in English), 2005.

[18] R. J. Assarabowski, W. T. Unkert, L. A. Bach, A. P. Grasso, and B. C. Olsommer, "Method and apparatus for preventing water in fuel cell power plants from freezing during storage," US Patent 6,797,421 B2, 2004. [Online]. Available: https://www.google.com/patents/US6797421

[19] M. Khandelwal, S. Lee, and M. M. Mench, "One-dimensional thermal model of cold-start in a polymer electrolyte fuel cell stack," Journal of Power Sources, vol. 172, no. 2, pp. 816-830, 10/25/ 2007, doi: http://dx.doi.org/10.1016/j.jpowsour.2007.05.028.

[20] Y. Zhou, Y. Luo, S. Yu, and K. Jiao, "Modeling of cold start processes and performance optimization for proton exchange membrane fuel cell stacks," Journal of Power Sources, vol. 247, pp. 738-748, 2014, doi: 10.1016/j.jpowsour.2013.09.023.

[21] L. Youcai, X. Sichuan, Y. Zhigang, and L. Youcai, "Experiment and simulation study on cold start of automotive PEMFC," in Electric Information and Control Engineering (ICEICE), 2011 International Conference on, 15-17 April 2011 2011, pp. 21662170, doi: 10.1109/ICEICE.2011.5776891.

[22] N. Henao, S. Kelouwani, K. Agbossou, and Y. Dubé, "Proton exchange membrane fuel cells cold startup global strategy for fuel cell plug-in hybrid electric vehicle," Journal of Power Sources, vol. 220, no. 0, pp. 31-41, 12/15/ 2012, doi: http://dx.doi.org/10.1016/j.jpowsour.2012.07.088.

[23] K. Jiao, I. E. Alaefour, G. Karimi, and X. Li, "Simultaneous measurement of current and temperature distributions in a proton exchange membrane fuel cell during cold start processes,"
Electrochimica Acta, vol. 56, no. 8, pp. 2967-2982, 3/1/ 2011, doi: http://dx.doi.org/10.1016/j.electacta.2011.01.019.

[24] F. Jiang and C.-Y. Wang, "Potentiostatic start-up of PEMFCs from subzero temperatures," Journal of the Electrochemical Society, vol. 155, no. 7, pp. B743-B751, 2008 2008, doi: 10.1149/1.2927381.

[25] R. Lin, Y. Weng, X. Lin, and F. Xiong, "Rapid cold start of proton exchange membrane fuel cells by the printed circuit board technology," International Journal of Hydrogen Energy, vol. 39, no. 32, pp. 18369-18378, 10/31/ 2014, doi: http://dx.doi.org/10.1016/j.ijhydene.2014.09.065.

[26] Q. Guo, Y. Luo, and K. Jiao, "Modeling of assisted cold start processes with anode catalytic hydrogen-oxygen reaction in proton exchange membrane fuel cell," International Journal of Hydrogen Energy, vol. 38, no. 2, pp. 1004-1015, 2013, doi: 10.1016/j.ijhydene.2012.10.067.

[27] R. Lin, Y. Weng, Y. Li, X. Lin, S. Xu, and J. Ma, "Internal behavior of segmented fuel cell during cold start," International Journal of Hydrogen Energy, vol. 39, no. 28, pp. 16025-16035, 9/23/2014, doi: http://dx.doi.org/10.1016/j.ijhydene.2013.12.083.

[28] R. K. Ahluwalia and X. Wang, "Rapid self-start of polymer electrolyte fuel cell stacks from subfreezing temperatures," Journal of Power Sources, vol. 162, no. 1, pp. 502-512, 11/8/ 2006, doi: http://dx.doi.org/10.1016/j.jpowsour.2006.06.071.

[29] F. Jiang, C. Y. Wang, and K. S. Chen, "Current ramping: A strategy for rapid start-up of PEMFCs from subfreezing environment," Journal of the Electrochemical Society, vol. 157, no. 3, pp. B342B347, 2010, doi: 10.1149/1.3274820.

[30] Y. Hishinuma, T. Chikahisa, F. Kagami, and T. Ogawa, "The design and performance of a PEFC at a temperature below freezing," JSME International Journal Series B Fluids and Thermal Engineering, vol. 47, no. 2, pp. 235-241, 2004.

[31] H. Meng, "Numerical studies of cold-start phenomenon in PEM fuel cells," Electrochimica Acta, vol. 53, no. 22, pp. 6521-6529, 9/20/ 2008, doi: http://dx.doi.org/10.1016/j.electacta.2008.04.044.

[32] G. Gwak and $\mathrm{H}$. Ju, "A rapid start-up strategy for polymer electrolyte fuel cells at subzero temperatures based on control of the operating current density," International Journal of Hydrogen Energy, vol. 40, no. 35, pp. 11989-11997, 9/21/ 2015, doi: http://dx.doi.org/10.1016/j.ijhydene.2015.05.179.

[33] A. A. Amamou, S. Kelouwani, L. Boulon, and K. Agbossou, "A Comprehensive Review of Solutions and Strategies for Cold Start of Automotive Proton Exchange Membrane Fuel Cells," IEEE Access, vol. 4, pp. 4989-5002, 2016, doi: 10.1109/ACCESS.2016.2597058.

[34] P. Liu and S. Xu, "A Progress Review on Heating Methods and Influence Factors of Cold Start for Automotive PEMFC System," 2020. [Online]. Available: https://doi.org/10.4271/2020-01-0852.

[35] S. Curtin and J. Gangi, "Fuel Cell Technologies Market Report," U.S. Department Of ENERGY, 2017.

[36] A. Amamou, L. Boulon, and S.Kelouwani, "Comparison of self cold start strategies of automotive Proton Exchange Membrane Fuel Cell," presented at the International Conference on Industrial Technology, Lyon, France, 2018.

[37] Q. Du, B. Jia, Y. Luo, J. Chen, Y. Zhou, and K. Jiao, "Maximum power cold start mode of proton exchange membrane fuel cell," International Journal of Hydrogen Energy, vol. 39, no. 16, pp. 8390-8400, 2014, doi: 10.1016/j.ijhydene.2014.03.056.

[38] M. Ibrahim, N. Y. Steiner, S. Jemei, and D. Hissel, "Wavelet-Based Approach for Online Fuel Cell Remaining Useful Lifetime Prediction," IEEE Transactions on Industrial Electronics, vol. 63, no. 8, pp. 5057-5068, 2016, doi: 10.1109/TIE.2016.2547358.

[39] D. Zhong et al., "Low temperature durability and consistency analysis of proton exchange membrane fuel cell stack based on comprehensive characterizations," Applied Energy, vol. 264, p. 114626, 2020.

[40] D. Zhou, A. Al-Durra, I. Matraji, A. Ravey, and F. Gao, "Online Energy Management Strategy of Fuel Cell Hybrid Electric Vehicles: A Fractional-Order Extremum Seeking Method," IEEE Transactions on Industrial Electronics, vol. 65, no. 8, pp. 67876799, 2018, doi: 10.1109/TIE.2018.2803723.

[41] N. Bizon, "Energy optimization of fuel cell system by using global extremum seeking algorithm," Applied Energy, vol. 206, pp. 458474, 2017/11/15/ 2017, doi: https://doi.org/10.1016/j.apenergy.2017.08.097. 
[42] K. Ettihir, L. Boulon, M. Becherif, K. Agbossou, and H. S. Ramadan, "Online identification of semi-empirical model parameters for PEMFCs," International Journal of Hydrogen Energy, vol. 39, no. 36, pp. 21165-21176, 2014/12/12/ 2014, doi: https://doi.org/10.1016/j.ijhydene.2014.10.045.

[43] T. Wang et al., "An optimized energy management strategy for fuel cell hybrid power system based on maximum efficiency range identification," Journal of Power Sources, vol. 445, p. 227333, 2020/01/01/

2020 ,

doi: https://doi.org/10.1016/j.jpowsour.2019.227333.

[44] A. Amamou, M. Kandidayeni, L. Boulon, and S. Kelouwani, " Real time adaptive efficient cold start strategy for proton exchange membrane fuel cells," Applied Energy, vol. 216, pp. 21-30, 2018/04/15 2018 ,

doi: https://doi.org/10.1016/j.apenergy.2018.02.071.

[45] M. Kandidayeni, A. Macias, A. A. Amamou, L. Boulon, S. Kelouwani, and H. Chaoui, "Overview and benchmark analysis of fuel cell parameters estimation for energy management purposes," Journal of Power Sources, vol. 380, pp. 92-104, 2018/03/15/ 2018, doi: https://doi.org/10.1016/j.jpowsour.2018.01.075.

[46] S. Strahl, A. Husar, and J. Riera, "Experimental study of hydrogen purge effects on performance and efficiency of an open-cathode Proton Exchange Membrane fuel cell system," Journal of Power Sources, vol. 248, pp. 474-482, 2014/02/15/ 2014, doi: https://doi.org/10.1016/j.jpowsour.2013.09.122.

[47] R. K. Ahluwalia and X. Wang, "Buildup of nitrogen in direct hydrogen polymer-electrolyte fuel cell stacks," Journal of Power Sources, vol. 171, no. 1, pp. 63-71, 2007/09/19/ 2007, doi: https://doi.org/10.1016/j.jpowsour.2007.01.032.

[48] S. Strahl, A. Husar, and M. Serra, "Development and experimental validation of a dynamic thermal and water distribution model of an open cathode proton exchange membrane fuel cell," Journal of Power Sources, vol. 196, no. 9, pp. 4251-4263, 2011/05/01/ 2011, doi: https://doi.org/10.1016/j.jpowsour.2010.10.074.

[49] M. Kandidayeni, A. M. F, L. Boulon, and S. Kelouwani, "Efficiency Enhancement of an Open Cathode Fuel Cell Through a Systemic Management," IEEE Transactions on Vehicular Technology, vol. 68, no. 12, pp. 11462-11472, 2019, doi: 10.1109/TVT.2019.2944996.

[50] S. Strahl, A. Husar, P. Puleston, and J. Riera, "Performance Improvement by Temperature Control of an Open-Cathode PEM Fuel Cell System," Fuel Cells, vol. 14, no. 3, pp. 466-478, 2014, doi: 10.1002/fuce.201300211.

[51] Q. Meyer et al., "Optimisation of air cooled, open-cathode fuel cells: Current of lowest resistance and electro-thermal performance mapping," Journal of Power Sources, vol. 291, pp. 261-269, 2015/09/30/ 2015, doi: https://doi.org/10.1016/j.jpowsour.2015.04.101.

[52] Y. Wang, P. P. Mukherjee, J. Mishler, R. Mukundan, and R. L. Borup, "Cold start of polymer electrolyte fuel cells: Three-stage startup characterization," Electrochimica Acta, vol. 55, no. 8, pp. 2636-2644, 3/1/ 2010, doi: http://dx.doi.org/10.1016/j.electacta.2009.12.029.

[53] R. H. Barton, T. D. Uong, C. J. Schembri, and G. A. Skinner, "Fuel cell purging method and apparatus," ed: Google Patents, 2005.

[54] V. Mishra, F. Yang, and R. Pitchumani, "Analysis and design of PEM fuel cells," Journal of Power Sources, vol. 141, no. 1, pp. 4764, 2005/02/16/ 2005, doi: https://doi.org/10.1016/j.jpowsour.2004.08.051.

[55] H. Penas. "Créer un plan d'expérience : méthode rapide et efficace (sans ANOVA)." http://3dc.asso-web.com/actualite-12-creer-unplan-d-experience-methode-rapide-et-efficace-sans-anova.html (accessed 21-12, 1017).

[56] J. Roberts, J. St-Pierre, M. van der Geest, A. Atbi, and N. Fletcher, "Methods for improving the cold starting capability of an electrochemical fuel cell," ed: Google Patents, 2003.

[57] C.-Y. Lee, Y.-M. Lee, and S.-J. Lee, "Local area water removal analysis of a proton exchange membrane fuel cell under gas purge conditions," (in eng), Sensors (Basel), vol. 12, no. 1, pp. 768-783, 2012, doi: $10.3390 / \mathrm{s} 120100768$.

[58] P. Xu and S. Xu, "A Progress Review on Gas Purge for Enhancing Cold Start Performance in PEM Fuel Cell," 2018. [Online]. Available: https://doi.org/10.4271/2018-01-1312.

[59] E. Thompson and R. Fuss, "Control system and method for starting a frozen fuel cell," ed: Google Patents, 2004.
[60] H. Y. Tang, A. D. Santamaria, J. Bachman, and J. W. Park, "Vacuum-assisted drying of polymer electrolyte membrane fuel cell," Applied Energy, vol. 107, pp. 264-270, 2013, doi: 10.1016/j.apenergy.2013.01.053.

[61] K. Tajiri, C.-Y. Wang, and Y. Tabuchi, "Water removal from a PEFC during gas purge," Electrochimica Acta, vol. 53, no. 22, pp. 6337-6343, 9/20/ 2008, doi: http://dx.doi.org/10.1016/j.electacta.2008.04.035.

[62] K. Tajiri, Y. Tabuchi, F. Kagami, S. Takahashi, K. Yoshizawa, and C.-Y. Wang, "Effects of operating and design parameters on PEFC cold start," Journal of Power Sources, vol. 165, no. 1, pp. 279-286, 2/25/2007, doi: http://dx.doi.org/10.1016/j.jpowsour.2006.12.017.

[63] A. K. Al-Othman, N. A. Ahmed, F. S. Al-Fares, and M. E. AlSharidah, "Parameter Identification of PEM Fuel Cell Using Quantum-Based Optimization Method," Arabian Journal for Science and Engineering, journal article vol. 40, no. 9, pp. 26192628, September 01 2015, doi: 10.1007/s13369-015-1711-0.

[64] F. Peng, L. Ren, Y. Zhao, and L. Li, "Hybrid dynamic modelingbased membrane hydration analysis for the commercial high-power integrated PEMFC systems considering water transport equivalent," Energy Conversion and Management, vol. 205, p. 112385, 2020/02/01/ 2020, doi: https://doi.org/10.1016/j.enconman.2019.112385.

[65] M. Kandidayeni, A. O. M. Fernandez, A. Khalatbarisoltani, L. Boulon, S. Kelouwani, and H. Chaoui, "An Online Energy Management Strategy for a Fuel Cell/Battery Vehicle Considering the Driving Pattern and Performance Drift Impacts," IEEE Transactions on Vehicular Technology, vol. 68, no. 12, pp. 1142711438, 2019, doi: 10.1109/TVT.2019.2936713.

[66] J. Jaguemont, L. Boulon, P. Venet, Y. Dubé, and A. Sari, "LithiumIon Battery Aging Experiments at Subzero Temperatures and Model Development for Capacity Fade Estimation," IEEE Transactions on Vehicular Technology, vol. 65, no. 6, pp. 4328-4343, 2016, doi: 10.1109/TVT.2015.2473841.

[67] M. Yue, S. Jemei, and N. Zerhouni, "Health-Conscious Energy Management for Fuel Cell Hybrid Electric Vehicles Based on Prognostics-Enabled Decision-Making," IEEE Transactions on Vehicular Technology, vol. 68, no. 12, pp. 11483-11491, 2019, doi: 10.1109/TVT.2019.2937130.

[68] H. Haas, S. Chor, L. I. Cosacescu, R. Rahmani, and C. Richards, "Systems and methods for fuel cell shutdown," ed: Google Patents, 2006.

[69] S. Ge and C.-Y. Wang, "Characteristics of subzero startup and water/ice formation on the catalyst layer in a polymer electrolyte fuel cell," Electrochimica Acta, vol. 52, no. 14, pp. 4825-4835, 4/1/ 2007, doi: http://dx.doi.org/10.1016/j.electacta.2007.01.038.

[70] S. Ge and C.-Y. Wang, "In situ imaging of liquid water and ice formation in an operating PEFC during cold start," Electrochemical and Solid-State Letters, vol. 9, no. 11, pp. A499-A503, 2006.

[71] K. Tajiri and C.-Y. Wang, "Cold Start of Polymer Electrolyte Fuel Cells," in Modeling and Diagnostics of Polymer Electrolyte Fuel Cells: Springer, 2010, pp. 89-128.

[72] R. L. Borup, J. R. Davey, F. H. Garzon, D. L. Wood, P. M. Welch, and K. More, "PEM fuel cell durability with transportation transient operation," in ECS Transactions, 2006, vol. 3, 1 ed., pp. 879-886, doi: 10.1149/1.2356206. [Online]. Available: http://www.scopus.com/inward/record.url?eid=2-s2.033846992585 \&partnerID $=40 \& \mathrm{md} 5=363 \mathrm{c} 68 \mathrm{ef} 1 \mathrm{fd} 3 \mathrm{a} 493 \mathrm{c} 438 \mathrm{bb} 2 \mathrm{~d} 8$ 96c1d35

[73] P. K. Sinha and C.-Y. Wang, "Gas purge in a polymer electrolyte fuel cell," Journal of The Electrochemical Society, vol. 154, no. 11, pp. B1158-B1166, 2007.

[74] J. C. Amphlett, R. F. Mann, B. A. Peppley, P. R. Roberge, and A. Rodrigues, "A model predicting transient responses of proton exchange membrane fuel cells," Journal of Power Sources, vol. 61, no. $1, \quad$ pp. 183-188, 1996/07/01/ 1996, doi: http://dx.doi.org/10.1016/S0378-7753(96)02360-9.

[75] Q. Li, T. Wang, C. Dai, W. Chen, and L. Ma, "Power Management Strategy Based on Adaptive Droop Control for a Fuel Cell-BatterySupercapacitor Hybrid Tramway," IEEE Transactions on Vehicular Technology, vol. 67, no. 7, pp. 5658-5670, 2018, doi: 10.1109/TVT.2017.2715178.

[76] A. M. Fernandez, M. Kandidayeni, L. Boulon, and H. Chaoui, "An Adaptive State Machine Based Energy Management Strategy for a Multi-Stack Fuel Cell Hybrid Electric Vehicle," IEEE Transactions 
on Vehicular Technology, vol. 69, no. 1, pp. 220-234, 2020, doi: 10.1109/TVT.2019.2950558.

[77] J. Larminie, "Efficiency and Open Circuit Voltage," in Fuel Cell Systems Explained, A. Dicks and Knovel Eds.: J. Wiley, 2003, pp. 25-43.

[78] L. Guzzella and A. Sciarretta, Vehicle Propulsion Systems: Introduction to Modeling and Optimization. Springer, 2005.

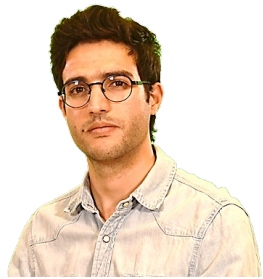

Ali Amamou (S'19) received the B.S. degree in Industrial Computing and automatic science from National Institute of Applied Sciences and Technology, Tunis, Tunisia, in 2013 and the M.S. degree in Embedded Systems Science from Arts et Métiers ParisTech University, Aix en Provence, France, in 2014. Between 2015 and 2018, he completed his $\mathrm{Ph} . \mathrm{D}$ degree in electrical engineering at Université du Québec à Trois-Rivières (UQTR), Canada. In May 2018, he started a postdoctoral fellow at the Hydrogen Research Institute. His main research interests are the optimization of energy systems for stationary and mobile applications, hybridization of energy sources for vehicular application and eco-energy navigation of low-speed autonomous electric vehicle.

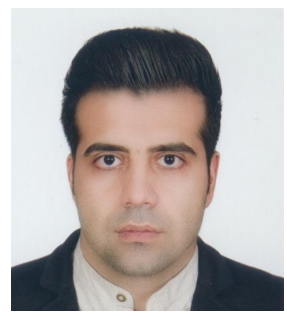

Mohsen Kandidayeni (S'18) was born in Tehran (Iran) in 1989. His educational journey has spanned through different paths. He received the B.S. degree in Mechanical Engineering in 2011, and then did a master's degree in Mechatronics at Arak University (Iran) in 2014. He joined the Hydrogen Research Institute of University of Quebec, Trois-Rivières, QC, Canada, in 2016 and received the Ph.D. degree in Electrical Engineering from this university in 2020. He was a straight-A student during his Master and Ph.D. programs and the recipient of a doctoral scholarship from the Fonds de recherche du Québec-Nature et technologies (FRQNT). His research interests include energy-related topics such as hybrid electric vehicles, fuel cell systems, energy management, Multiphysics systems, modeling and control.

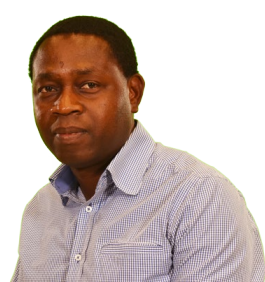

Sousso Kelouwani (M'00-SM'17) received the B.S. and the M.Sc.A. degrees from Université du Québec à Trois-Rivières, Trois-Rivières, QC, Canada, in 2000 and 2002, respectively, and the Ph.D. degree (automation and systems) from École Polytechnique de Montréal, Montréal, QC, Canada, in 2010, all in electrical engineering. Holder of the Industrial Research Chair DIVEL in Intelligent Navigation of Autonomous Industrial Vehicles, Sousso Kelouwani is a full professor of Mechatronics at the Department of Mechanical Engineering at UQTR (since 2018). Before starting his doctoral studies, he worked in research and development in the field of cell phone application optimization for Cilys 53 inc. (2002-2005) and Openwave inc. (2005-2006). Holder of three patents in the United States, his research interest focuses on the optimization of energy systems for vehicular applications, advanced driving assistance techniques, eco-energy navigation of autonomous vehicles, hybridization of energy sources for vehicles with low ecological impact (battery, fuel cell, hydrogen generator, etc.) in harsh weather conditions. In 2017, he received the Environment Award of the Grand Prix for Excellence in Transport from the Quebec Transportation Association (AQTr) for the development of a hydrogen range extender based on a hydrogen generator for electric vehicles. He was also a recipient of the Canada Governor General's Gold Medal in 2000. Moreover, he has worked with several Canadian transportation companies to develop intelligent, energy-efficient and driverless vehicles.

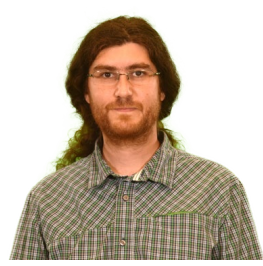

Loïc Boulon (M'10, SM'16) received the master's degree in electrical and automatic control engineering from the University of Lille (France), in 2006. Then, he obtained a $\mathrm{PhD}$ in electrical engineering from University of Franche-Comté (France). Since 2010, he is a professor at Université du Québec à TroisRivières (Canada) and he works at the Hydrogen Research Institute (Full Professor since 2016). His work deals with modeling, control and energy management of multiphysics systems. His research interests include hybrid electric vehicles, energy and power sources (especially battery in cold weather operation), and fuel cell systems. He has published more than 100 scientific papers in peer-reviewed international journals and international conferences. In 2015, Loïc Boulon was general chair of the IEEE-Vehicular Power and Propulsion Conference in Montréal (QC, Canada). Prof. Loïc Boulon is VP-Motor Vehicles of the IEEE Vehicular Technology Society and he is the holder of the Canada Research Chair in Energy Sources for the Vehicles of the future. 